\title{
Feasibility of the use of mineral wool fibres recovered from CDW for the reinforcement of conglomerates by study of their porosity
}

\author{
Carolina Piña Ramírez ${ }^{\mathrm{a}, *}$, Evangelina Atanes Sánchez ${ }^{\mathrm{b}}$, Mercedes del Río Merino ${ }^{\mathrm{a}}$, \\ Carmen Viñas Arrebola ${ }^{c}$, Alejandra Vidales Barriguete ${ }^{c}$ \\ a Universidad Politêcnica de Madrid, Escuela Técnica Superior de Edificación, Departamento de Construcciones Arquitectónicas y su Control, Avda. Juan de Herrera, 6, \\ 28040 Madrid, Spain \\ ${ }^{\mathrm{b}}$ Universidad Politécnica de Madrid, Escuela Técnica Superior de Ingeniería y Diseño Industrial, Departamento de Ingeniería Mecánica, Química y Diseño Industrial, \\ Ronda de Valencia 3, 28012 Madrid, Spain \\ ${ }^{c}$ Universidad Politécnica de Madrid, Escuela Técnica Superior de Edificación, Departamento de Tecnología de la Edificación, Avda. Juan de Herrera, 6, 28040 Madrid, Spain
}

- The addition of mineral fibres waste does not affect the functionality of mortars.

- The porous structure of admixed fibres mortars is similar to that of the reference.

- Waste mineral fibres are an alternative to current commercial reinforcements.

- Mortars reinforced with mineral fibres waste minimize environmental impact.

\begin{abstract}
A B S T R A C T
Mineral wool is currently the most used insulation in the European Union, and quantities of this waste have increased alarmingly in the last decade, making it essential to recycle or reuse the material, which is not current practice. This study aims to verify the feasibility of compounds of a cement base with additives of insulating mineral fibre residues recovered from the recycling of construction and demolition waste (CDW). For this purpose, experiments were designed to classify the physical-chemical behaviour of architectural mineral wool waste, and that of mortars incorporating them to determine their porosity due to the effects of these fibres on the properties of the compounds. The results obtained show that both the structure and chemical composition as well as the microstructure of the reinforced mortars are viable, and that they would therefore be a sustainable alternative to the current mortars of composite materials
\end{abstract}

\section{Introduction}

The construction sector has a huge environmental impact, as it uses $60 \%$ of the raw materials extracted from the lithosphere [1], and in recent decades has generated large amounts of construction and demolition waste (CDW). This enormous amount of waste is one of the main indicators of the unsustainability of the sector, as it is estimated that around 890 million tons of CDW are produced in Europe every year; of which only $50 \%$ are recycled $[2,3]$. The current European economic model, based on the linear process

* Corresponding author at: Technical University of Madrid, Avda. Juan de Herrera, 6, 28040 Madrid, Spain.

E-mail address: carolina.pina@upm.es (C. Piña Ramírez). of "take-make-use-remove" is no longer sustainable [4]. It is therefore essential to change to a model based on a circular economy, in which the waste generated is reduced and the value of resources is maintained for as long as possible [5], in line with the Europe 2020 [6] structural economic strategy proposed by the European Union.

When applied to the construction sector, this new model implies considering the entire life cycle of buildings, from the initial phases that include the obtaining of raw materials and specifications for construction [7], through construction of the building, its use, maintenance, and, finally, the management of waste generated by its demolition, with special consideration given to its reuse or recycling [8]. It is this last phase of the life cycle that this paper explores, because the high cost of waste management, as is the 
case with insulating mineral wool materials, and the environmental impact of contamination due to its discharge are factors to avoid. Furthermore, the impact of this construction and demolition waste extends to the greenhouse gases produced in landfills [9], responsible for $3-4 \%$ of total global emissions.

This research intends that mineral wool waste replace part of the mortar aggregate. This is a fundamental issue if we consider that the extraction of sand worldwide has skyrocketed in the last 30 years being the most demanded natural resource in the world after water, especially by the construction sector that demands about $85 \%$ of it.

Insulation materials are key to designing and constructing buildings that are more energy efficient [10]. Specifically, mineral wool is currently the most used insulation in the European Union; thermal and acoustic insulation solutions for buildings have been designed using toxic or hard-to-recycle mineral wool [11], and this is still the case today. Thus, the amount of waste rockwool dumped in landfills has increased dramatically in the last decade [12], making it essential to recycle or reuse the material.

It is difficult to accurately calculate the amount of this waste generated over a certain period, but according to the model applied by Väntsi it can be estimated that in 2020 more than 2.5 million units of mineral wool waste will be generated in the EU-28 zone [13], although the percentage of recovery, recycling or reuse is not known.

Traditionally, the inclusion of fibres in mortar compounds has evolved along with the development of knowledge and techniques related to mortar fabrication, determining the ratio or proportions of the fibres and the type of mortar in the mix according to its function and purpose in the building [14].

To date, various studies on the recycling and reuse of mineral wool waste have been done, but they are scarce [15]. One of the problems presented by cement-based composite materials is the change that occurs in their porosity due to the interaction of additive materials [16]. These changes in porous structure can affect the density, water absorption and thermal conductivity, as well as the mechanical properties [17] and strength of the compounds [18]. Almost all solid materials have some level of porosity, and it has been shown that the mechanical strength of building materials is directly related to their porosity, pore size distribution [19], and the length of fibres [20]. No existing studies have analysed the change in porosity, even though any increase would directly affect the mechanical strength of a material due to the implied reduction in resistant volume/mass [21]. This porosity, or average porosity, is determined by the size of the particles and their level of compaction, and its importance depends on the intended use for the material analysed.

In this context it is understandably meaningful to study the feasibility of using recycled fibres in the reinforcement of cement mortars, with respect to any effects on the crystalline and porous structure of the material, thus not only reducing the CDW generated by the construction industry and its consumption of raw materials, of serious environmental impact, but also providing an alternative to the fibres currently used for reinforcing mortar and concrete.

No in-depth research has been found on the incorporation of different types of mineral wool waste in cement-based compounds [15], while there are studies of similar characteristics looking at plaster [22] and polypropylene compounds [23].

In addition, based on a review of the available literature, the obstacles to recycling mineral wool include economic issues, aspects related to the purity and health effects of mineral wool waste, and, in the area of this study, the difficulty of transforming the fibres into an appropriate format for incorporation into the mixtures. Another factor assessed is whether the material properties of mineral wool waste, such as thermal insulation and fire resistance, could provide improved properties in products that use mineral wool waste as a raw material [11], in cement mortars in the case of this study.

This paper presents some of the results obtained from a research project designed to analyse the feasibility of using fibres from mineral wool panels for reinforcement in cement mortars used in construction, as an alternative to the typically used AR glass fibres (alkali resistant) $[24,25]$ and polymeric fibres $[26,27]$.

In short, this is a classification of both the raw materials and the mortar compounds made to study their feasibility of use, from the point of view of porous structure. This could, therefore, represent an interesting alternative to the commercial fibres currently used to reinforce concretes and mortars, the objective of which is to obtain products of greater flexibility and lightness.

\section{Materials and methods}

\subsection{Materials}

The materials used in this study are Portland cement Cem II/B-L $32,5 \mathrm{~N}$ (supplied by the company Cementos Portland Valderrivas, Madrid, Spain), river sand of $4 \mathrm{~mm}$ sieve diameter, and three types of mineral wool waste: fiberglass, rockwool, and mixed mineral wool waste.

The mineral wool waste used in this work came from the Centre for the Collection and Treatment of the Construction and Demolition Waste located in El Molar (Madrid, Spain), and managed by the company Gedesma S.A. The fibres were piled outdoors mixed with other residues and were separated from them manually. Afterwards the rockwool waste and fiberglass wool waste were separated and constitute the samples called RW and FG respectively. A third sample is constituted for the rockwool and fiberglass wool waste mixed as they found in the landfill, and it is called MIX at this work.

The three types of mineral fibre waste underwent a pretreatment in this study: they were crushed in a machine of $550 \mathrm{~W}$ power at $50 \mathrm{~Hz}$, for three intervals of $3 \mathrm{~min}$ each, putting them into a suitable form for incorporation into the mortars.

A series of test samples were made with the three types of fibre waste, adding them to replace a $30 \%$ of the river sand measured by volume.

The $30 \%$ is the highest amount of fibres in the samples to remain workable. Workability means the ease with which the mixture can be handled without segregation problems, without setting or drying, retaining enough water for its correct put in work. The different prismatic test samples of dimensions $4 \times 4 \times 16 \mathrm{~cm}$ (Fig. 1) were made following rigorous guidelines according to the standards UNE EN1015-2: 1999 [28] and UNE EN1015-11: 2000 [29]. Three specimens were made for each of the four batch with the three types of fibre waste.

While these standards do not specifically provide for the manufacture of mortars admixed with fibres, the procedure followed the indications in terms of rigor and standardization of the tests, such that the study could be reproduced and the trials could be used for comparison in future research.

Thus, the additive fibres were first introduced into the water, then the cement added, and the mix kneaded manually for $15 \mathrm{~s}$. The mixer was then started to mix the components at a slow speed for $15 \mathrm{~s}$, and then the aggregate added, and the mixer switched to rapid kneading for $75 \mathrm{~s}$. Once the mixing process was finished, the consistency of each of the mixtures was determined by measuring the runoff value as specified in the standard.

After $24 \mathrm{~h}$ curing in a humid chamber at a temperature of $20^{\circ} \mathrm{C}$ and a relative humidity of $95 \%$, the samples were removed from their moulds, and then returned to the humid chamber to remain 

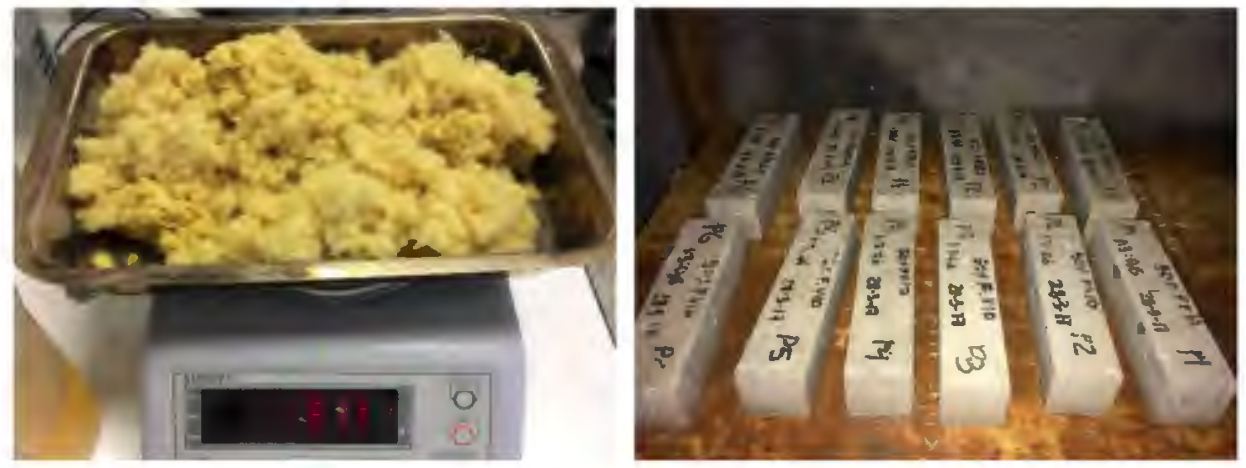

Fig. 1. Fibreglass waste, and prismatic test samples.

there for a total of 28 days to reach the hardness necessary to be submitted to the different tests.

According to the bibliography reviewed and previous tests the dosage for all samples was 1:3:0.6 (cement:sand:water). A prismatic test sample of mortar without fibres was prepared for comparison purposes, and it is called Reference sample.

\subsection{Experimental plan}

The experimental plan comprised a study on the feasibility of waste for incorporation into a cement mortar matrix, analysed through an evaluation of its structure and porous microstructure. The procedure designed for this purpose had two-stages: a first stage in which the raw materials are analysed by X-ray fluorescence, X-ray diffraction (XRD), differential thermal and thermal gravimetric analysis (DTA/TGA), scanning electron microscopy, and bulk density; and a second phase in which the mortars admixed with fibres are evaluated using XRD, TGA-DSC, scanning electron microscopy, mercury porosimetry, and nitrogen adsorption-desorption.

For the chemical analysis, the mortar samples were crushed to obtain a powdered sample. Additionally, for same analysis (XRD, thermogravimetric analysis, and $\mathrm{N}_{2}$ adsorption-desorption experiments) the mortar crushed sample were manually milled and sieved to produce homogeneous powdered samples.

The chemical composition has been analysed by XRF using a Philips-Magix equipment of $1 \mathrm{~kW}$. The samples were covered with Mylar film and analysed in He atmosphere.

X-ray diffraction patterns were obtained in a Siemens Krystalloflex D5000 unit using a graphite monochromator with $\mathrm{Cu} \mathrm{K} \alpha$ $(1,2)$. The samples were scanned over the range $5^{\circ} \leq 2 \theta \leq 100^{\circ}$ every $0.04^{\circ}, 4$ s per step.

DTA/TGA was carried out in a SDT Q600 unit (TA Instruments). 20-30 $\mathrm{mg}$ of sample were ramped from room temperature to $1300^{\circ} \mathrm{C}$ at $10^{\circ} \mathrm{C} \mathrm{min}^{-1}$ in a $100 \mathrm{~cm}^{3} \mathrm{~min}^{-1}$ flow of air previously filtered.

The bulk density of raw materials was determined with a test tube. The bulk density of the hardened mortars was calculated based on the volume of the samples and their dry mass after 28 days of setting.

The microstructural characterization of the materials was achieved using a FEI QUANTA FEG 250 high resolution electronic microscope.

The porosimetry test was carried out by mercury injection into cylindrical test samples of mortar ( $1 \mathrm{~cm}$ high by $1 \mathrm{~cm}$ in diameter). extracted by means of a drill, using an AutoPore IV 9500 porosimeter from Micromeritics. One porosimetry test was done for each batch.

The $\mathrm{N}_{2}$ adsorption-desorption isotherms of mortars have been obtained in a Micromeritics 3Flex CHEMI TCD at $-196^{\circ} \mathrm{C}$. The sam- ples have been outgassed for $13 \mathrm{~h}$ previously to the measurement. From these data the BET surface, total pore volume and pore size distribution have been obtained.

\section{Results and discussion}

\subsection{Raw materials characterization}

The chemical composition of the mineral wool wastes and cement is presented in Table 1 and it is similar to the results of the bibliography both for commercial fibres or those synthesized in the laboratory and for waste fibres $[14,23,30]$. The main component in both materials is $\mathrm{SiO}_{2}$ (around 70\%) followed by $\mathrm{CaO}$ as the second one (around 20\%). Also $\mathrm{Na}, \mathrm{Al}, \mathrm{K}$ and Fe oxides are present in lower quantities.

The mix sample presents an intermediate composition among the rock wool and the glass fibre wool. The composition of mineral fibres is similar to that of the supplementary cementing materials (SCMs) such as fly ash and silica fume, making it an adequate substitute for the coarse and fine aggregates in a cement-base composite [14].

The XRD pattern of the fibres (Fig. 2) does not shown any reflection due to crystalline structures as it is fully amorphous [30].

The mineral wools used in the study have cylindrical and fibriform shape as evidenced by the pictures taken with a scanning electron microscope (Fig. 3).

The physical characterization of the fibres is presented in Table 2 being the distribution of the diameter of fibres according to the bibliography $[23,30]$. The bulk density of the fibres is extremely low due to its woollen nature and the mix sample present intermediate values among the RW and FG samples.

Fig. 4 show the thermal analysis for the MIX sample being the thermal behaviour of the other fibres samples used in the work very similar. The evolution of weight with the temperature under the flow of air presents a noisy line; this behaviour is attributed to the loose packing due to the low bulk density of the samples.

The MIX fibres show a broad weight loss of about $10 \%(20 \%$ for FG, and $5 \%$ for RW samples) a temperatures less than $500^{\circ} \mathrm{C}$ that can be associated to the decomposition of organics additives used in the manufacture of fibres [30,31]; the event shows three peaks in the derivative curve of weight vs. temperature indicative of the combustion of several organic compounds as indicated by the minor exothermic effects in the heat flow curve. Around $690^{\circ} \mathrm{C}$ there is a small exothermic event that could be assigned to the devitrification of glassy fibres with the formation of crystalline phases [30,32]. Around $1000-1100^{\circ} \mathrm{C}$ there is an endothermic process not finished during the analysis that can be attributed to the melting of these new formed crystals; the effect is accompanied with a weight loss that could indicate partial decomposition/ volatilization of the sample. 
Table 1

Chemical composition of cement, sand and fibres.

\begin{tabular}{|c|c|c|c|c|c|}
\hline & CEM II 32.5B-L & Sand & Rock wool & Fibre glass & Mixture \\
\hline \multicolumn{6}{|c|}{ Concentration [\%] greater than $0.01 \%$} \\
\hline $\mathrm{CaO}$ & 72.80 & - & 22.60 & 20.00 & 20.40 \\
\hline $\mathrm{Fe}_{2} \mathrm{O}_{3}$ & 8.65 & - & 1.36 & 1.44 & 1.92 \\
\hline $\mathrm{SO}_{3}$ & 3.76 & - & 5.73 & 1.12 & 2.51 \\
\hline $\mathrm{SiO}_{2}$ & 10.00 & 85.89 & 60.10 & 66.20 & 64.30 \\
\hline $\mathrm{Al}_{2} \mathrm{O}_{3}$ & 2.05 & 10.08 & 0.76 & 3.48 & 1.42 \\
\hline $\mathrm{K}_{2} \mathrm{O}$ & 0.67 & 3.05 & 0.58 & 2.82 & 1.01 \\
\hline $\mathrm{TiO}_{2}$ & 0.64 & - & 0.20 & 0.08 & 0.24 \\
\hline $\mathrm{Ba}$ & 0.53 & - & 1.07 & - & 0.54 \\
\hline $\mathrm{MgO}$ & 0.39 & - & 1.39 & 1.76 & 1.08 \\
\hline $\mathrm{Sr}$ & 0.22 & - & 0.07 & 0.21 & 0.10 \\
\hline $\mathrm{Mn}$ & 0.18 & - & 0.18 & - & 0.37 \\
\hline $\mathrm{Zn}$ & 0.05 & - & 0.19 & 0.02 & 0.10 \\
\hline $\mathrm{Cu}$ & 0.35 & - & - & - & - \\
\hline $\mathrm{Rb}$ & 0.02 & - & - & 0.05 & 0.02 \\
\hline $\mathrm{Na}_{2} \mathrm{O}$ & - & - & 5.29 & 2.76 & 5.72 \\
\hline $\mathrm{Cl}$ & - & - & 0.28 & - & 0.19 \\
\hline $\mathrm{Cr}$ & - & - & 0.52 & - & 0.13 \\
\hline
\end{tabular}

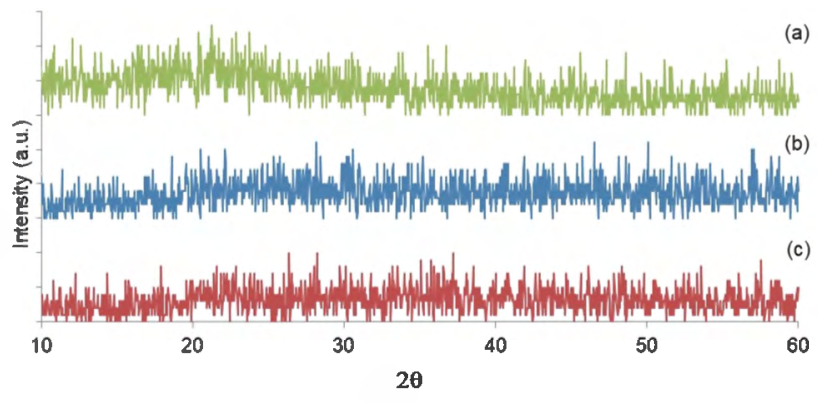

Fig. 2. XRD of fibres: (a) rockwool, (b) fibre glass wool, and (c) mixture.

These results indicate that the physical and chemical characteristics of fibre waste have not been altered through the typical process of storage in a landfill, and thus they are suitable for use.

Tables 1 and 2 and Figs. 4 and 5 present the chemical and physical characterization of the cement. The fundamental components of the cement analysed are $\mathrm{Si}, \mathrm{Ca}, \mathrm{Al}$ and Fe oxides, according to the four principal phases contained in the Portland cement clinker: tricalcium silicate (alite, C3S), dicalcium silicate (belite, C2S), tricalcium aluminate (C3A) and tetracalcium aluminoferrite (C4AF) being the most abundant phases alite (50-70\%) and belite $(15-30 \%)[14,33]$. The CaO content is very high because it is a type II cement containing limestone (calcium carbonate) as an additive. Ordinary Portland cement is produce by grinding the clinker with a permitted amount of gypsum that is reflected in the presence of sulphur in a low proportion in the chemical analysis.
Table 2

Physical properties of raw materials.

\begin{tabular}{|c|c|c|c|}
\hline & \multirow{2}{*}{$\begin{array}{l}\text { Bulk density } \\
\left(\mathrm{g} / \mathrm{cm}^{3}\right)\end{array}$} & \multicolumn{2}{|c|}{ Fibres size } \\
\hline & & $\begin{array}{l}\text { Width } \\
(\mu \mathrm{m})\end{array}$ & $\begin{array}{l}\text { Length } \\
(\mu \mathrm{m})\end{array}$ \\
\hline Rock wool & 0.01 & $8-9$ & $500-1000$ \\
\hline Fibre glass wool & 0.06 & $15-20$ & $500-900$ \\
\hline Mixture & 0.03 & $8-20$ & $500-1000$ \\
\hline Cement & 1.00 & & \\
\hline River sand $0 / 4$ & 1.61 & & \\
\hline
\end{tabular}

In accordance with this, the X-ray diffractogram identifies the phases of calcium carbonate (calcite), corresponding to the most intense peak, and calcium silicates (alite and belite), as well as those of $\mathrm{Ca}(\mathrm{OH})_{2}$ formed during the storage of the cement $[15,34]$.

This high calcite content is also evident in the thermal analysis (Fig. 4), being the thermal decomposition of $\mathrm{CaCO}_{3}$ to obtain $\mathrm{CaO}$ the main thermal event, corresponding to a loss of mass of approximately $8 \%$, between approximately $500^{\circ} \mathrm{C}$ and $800^{\circ} \mathrm{C}$, of an endothermic nature. This loss of mass would correspond to an $18 \%$ limestone content in the cement.

Two small mass losses associated with exothermic events at temperatures below $500^{\circ} \mathrm{C}$ are also seen in the analysis. The first endothermic event occurring at low temperature, below $150^{\circ} \mathrm{C}$, with a mass loss of around $0.5 \%$, reaching its peak at approximately $110^{\circ} \mathrm{C}$, which could be associated with the dehydration of the gypsum dihydrate or hemihydrate. The second loss, of around $0.2 \%$, due to an endothermic event between $400^{\circ} \mathrm{C}$ and $500^{\circ} \mathrm{C}$, peaking at $440^{\circ} \mathrm{C}$, would correspond to the dehydration of $\mathrm{Ca}(\mathrm{OH})_{2}$,
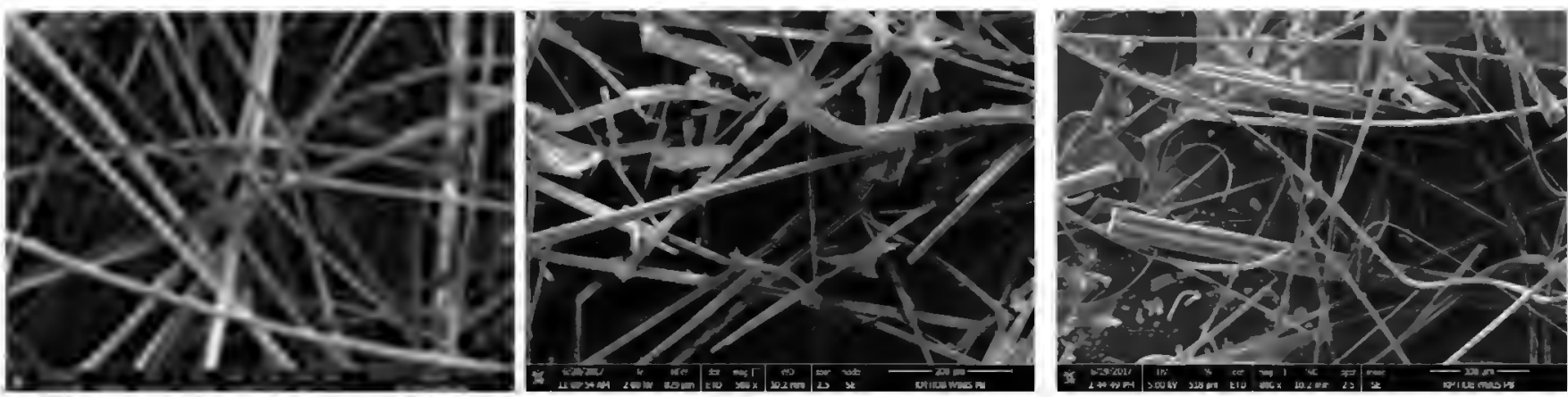

Fig. 3. SEM micrographs for the fibres (from left to right): rockwool, fibre glass wool, and mixture. 

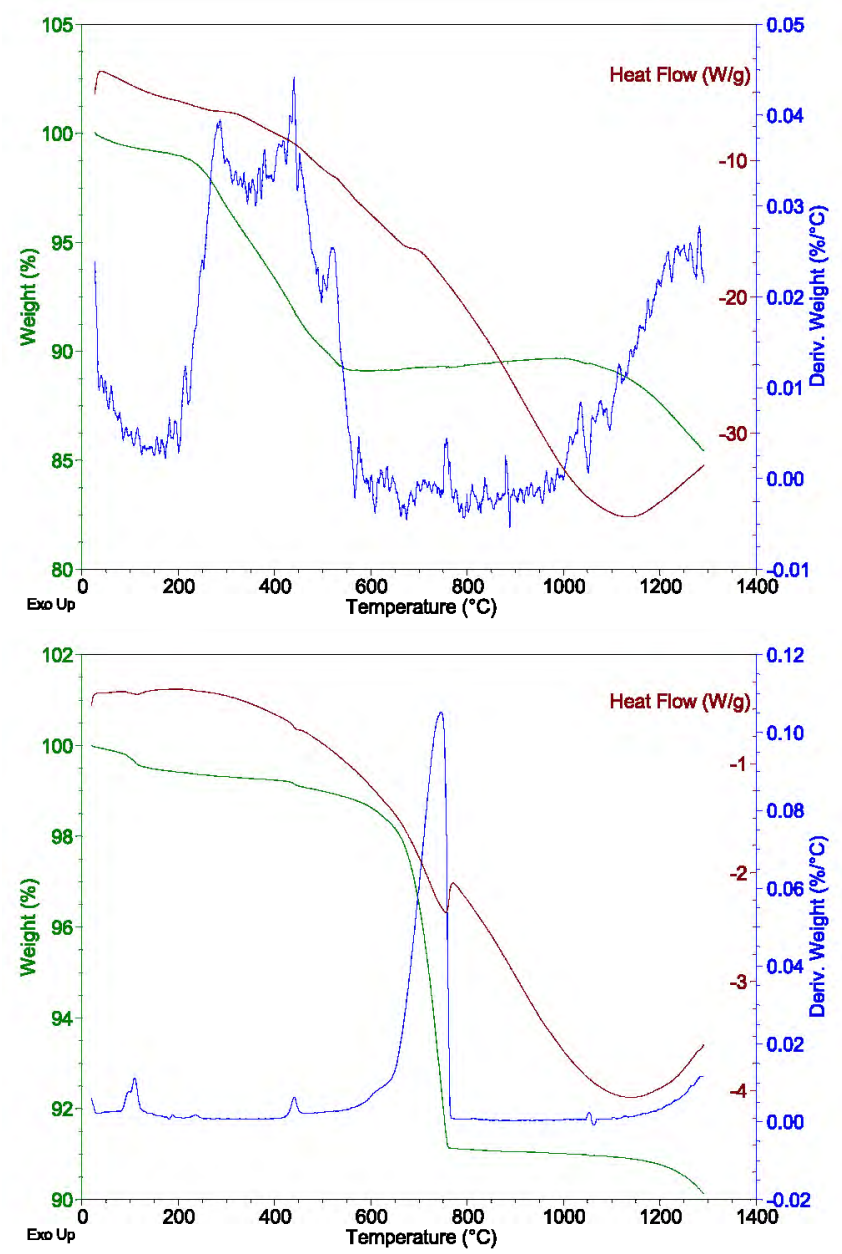

Fig. 4. Thermal analysis of raw materials: MIX fibres (top) and cement (bottom).

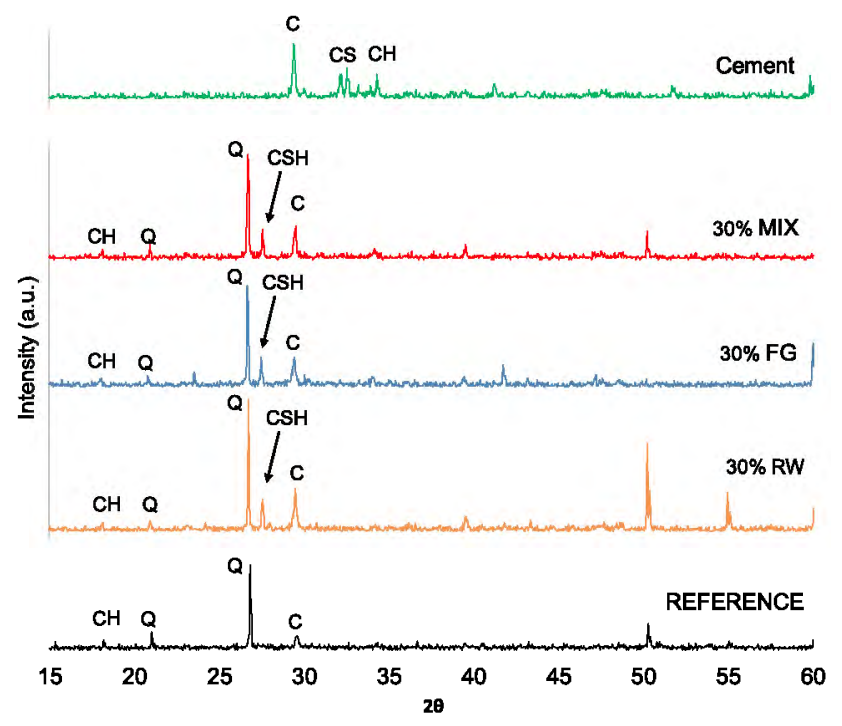

Fig. 5. XRD of cement, admixed and reference mortars. Q: quartz; C: calcite; CS: calcium silicates; $\mathrm{CH}$ : calcium hydroxide; $\mathrm{CSH}$ : hydrated phases of calcium silicates.

representing an approximate amount of $0.9 \mathrm{wt} \%$ in the cement. The thermal events observed are thus mainly related to the cement additives, as the components of the cement clinker are stable at temperatures below $1000^{\circ} \mathrm{C}$ given that the clinkerization process happens at higher temperatures [35].

\subsection{Characterization of mortars admixed with mineral wool waste}

Fig. 5 presents the X-ray diffractograms for the reference and admixed mortar samples. The graphs reveal that the peaks of higher intensity in all mortars are due to the sand and correspond to the crystalline quartz, at the diffraction angles of $21.0^{\circ}$ and $26^{\circ}$. Also, the peaks of calcite originally present in the cement at the diffraction angles of $29^{\circ}$ and $39^{\circ}$ are observed [36,37].

During the hydration of the cement the alite (C3S) and belite (C2S) form hydrated calcium silicates, called calcium-silicate-hy drate (CSH) phases, with variable stoichiometry which are responsible of the mechanical strength of the mortars [35]. The hydration of both alite and belite results in the accompanying formation of calcium hydroxide $\mathrm{Ca}(\mathrm{OH})_{2}$, named phase $\mathrm{CH}$.

According to that, the X-ray diffractogram shows the peak of CSH phases at diffraction angles comprised between $21^{\circ}$ and $29^{\circ}$, and the peak of $\mathrm{CH}$ phase at diffractions angles of $17.9^{\circ}$ and $34.2^{\circ}$. The intensity of the peaks corresponding to the products of the hydration reactions is low because these materials present low crystallinity, especially the CSH phase. Therefore, this phase it is not always detected by XRD although it is the main product of the hydration reaction [38]. In this line, the diffractogram of the reference mortar sample does not present the peaks of the $\mathrm{CSH}$ although the phase is detected in this sample by thermogravimetric analysis as described below. As a summary of the XRD results, no new hydration reactions or substantial changes are detected in the mortars by the inclusion of the mineral fibres in their composition. The thermogravimetric analysis results are presented in Fig. 6.

To explain these results there is need to take into account the way of preparation of the prismatic samples of mortars. In reference and admixed specimen the mass of cement and water is the same. In the admixed mortars the $30 \%$ of the volume of the sand has been replaced for fibres with respect to the reference sample. Due to the low bulk density of the fibres the total mass of sand + fibres, and consequently the total mass of the reference sample is higher than in the admixed mortars. Thus, the mass of cement account for a higher wt\% in admixed samples compared with the reference one, and the mass of fibres in the mortar pastes as prepared account for 2.2, 0.6 and $1.4 \mathrm{wt} \%$ (dry basis) respectively for FG, RW and MIX admixed mortars samples.

Fig. 6a presents the TG curve results with the total mass loss. The derivative thermogravimetric (DTG) and differential thermal analysis (DTA) in Fig. 6b and c shows additional information about the individual events. TG can be used to determine quantitatively the mass loss of liquid $\left(\mathrm{H}_{2} \mathrm{O}\right)$ or gas $\left(\mathrm{CO}_{2}\right)$ of the hydrated phases of compounds.

Accordingly, with the mass composition of the investigated specimen (wt\% of cement is higher in mortars including fibres), the total mass loss in the blended samples is higher (around 17$22 \%$ ) than in the reference sample (around $12 \%$ ) because the mass loss event are related mainly with the decomposition or dehydration of compounds from the mortar as described below.

The reference mortar and fibre containing mortars show three mass loss events, with the first being from room temperature to $\approx 400^{\circ} \mathrm{C}$, the third from $\approx 400$ to $500^{\circ} \mathrm{C}$ and the last one from $\approx 500$ to $800^{\circ} \mathrm{C}$. In the first transition until $400^{\circ} \mathrm{C}$ water is lost either as free water remaining in the specimen after setting or from the dehydration of the calcium and aluminium silicate compounds (C-S-H phase) formed during the hydration of Portland cement. Specially in the zone under $200^{\circ} \mathrm{C}$ is clearly observed in the DTG curves of all samples two maximum at temperatures of 75 and $125^{\circ} \mathrm{C}$, endothermic events as it is seen DTA curves, and attributed 

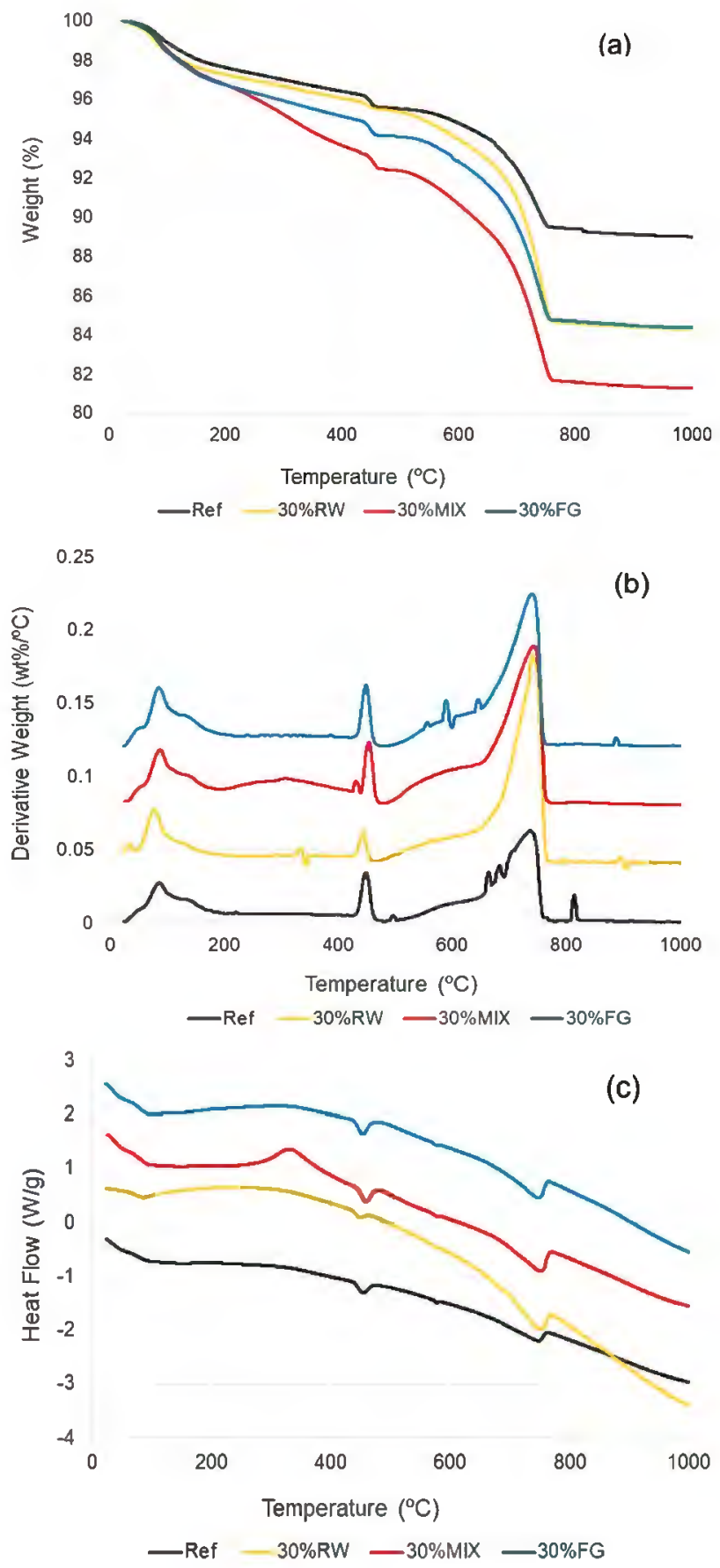

Fig. 6. Thermal analysis of reference and admix mortars: (a) total mass loss vs. temperature, (b) derivative loss mass vs. temperature (axis adjusted for clarity), (c) thermal events vs. temperature with exothermal event up (axis adjusted for clarity).
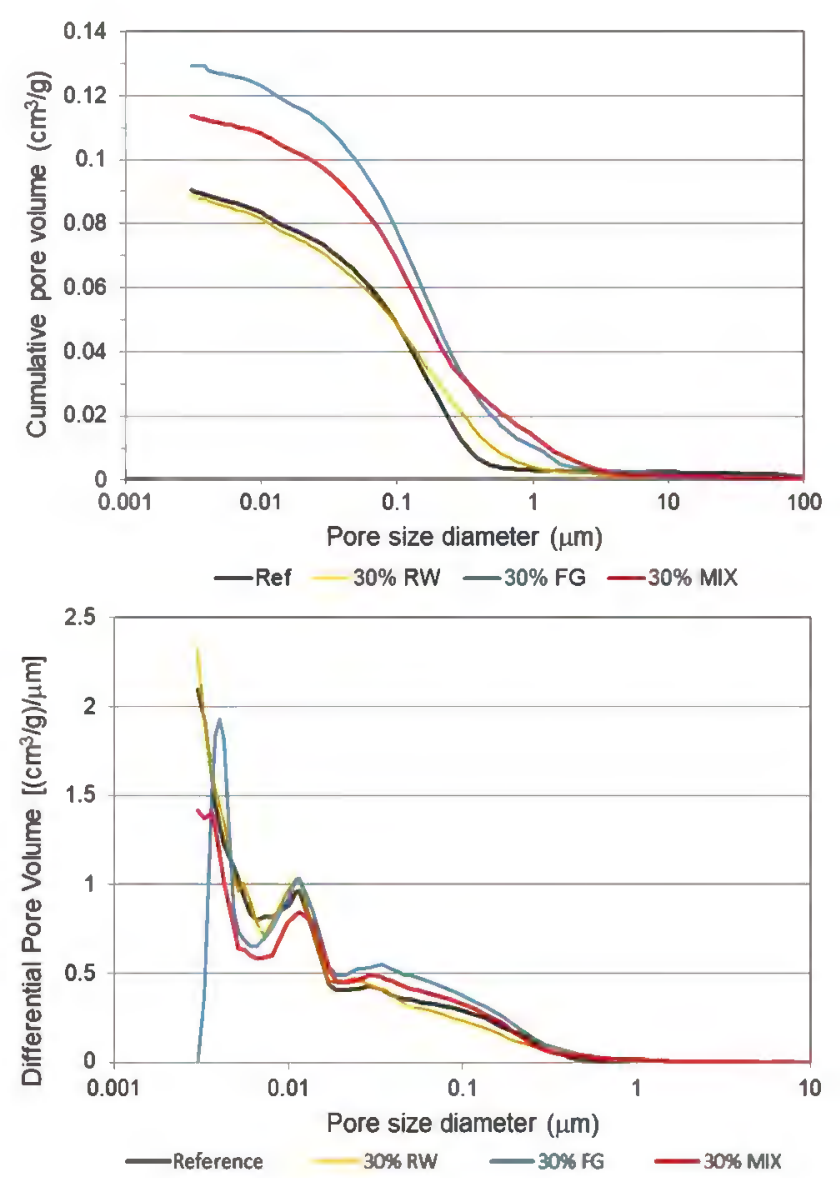

Fig. 7. Cumulative (a) and differential (b) pore volume obtained by mercury porosimetry.

to the dehydration of ettringite $\left(6 \mathrm{CaO} \cdot \mathrm{Al}_{2} \mathrm{O}_{3} \cdot 3 \mathrm{SO}_{3} \cdot 32 \mathrm{H}_{2} \mathrm{O}\right)$, or others compounds such as gehlenite hydrate [35,37].

The second mass event show a maximum in the DTG curve at $442-448{ }^{\circ} \mathrm{C}$ for all samples, endothermic event in the DTA curve, corresponding to the decomposition of the $\mathrm{Ca}(\mathrm{OH})_{2}$ (phase $\mathrm{CH}$ ) also formed in the reaction of Portland cement with water. The $\mathrm{Ca}(\mathrm{OH})_{2}$ decomposes to give $\mathrm{CaO}$ and $\mathrm{H}_{2} \mathrm{O}$, and that account for a loss mass less than $1 \mathrm{wt} \%$ of the total mass of mortars.

The third mass loss in the region of $500-800^{\circ} \mathrm{C}$ present an asymmetric decomposition peak in the DTG curve with a maximum at $\approx 724-730^{\circ} \mathrm{C}$ in all samples and correspond to the endothermal decomposition (see DTA curve) of $\mathrm{CaCO}_{3}$ to give also $\mathrm{CaO}$ and $\mathrm{CO}_{2}$. The $\mathrm{CaCO}_{3}$ come from the cement and also can be produced in aged concrete from the slow carbonation reaction of $\mathrm{Ca}(\mathrm{OH})_{2}$ phase of the mortar with the atmospheric $\mathrm{CO}_{2}$. This event is the most important in all samples and account for about $6 \mathrm{wt} \%$

Table 3

Microstructural characterization of reference and admixed mortars.

\begin{tabular}{|c|c|c|c|c|c|c|c|c|}
\hline & \multicolumn{5}{|c|}{ Hg porosimetry } & \multicolumn{2}{|c|}{$\begin{array}{l}\text { Adsorption-desorption } \\
\mathrm{N}_{2} \\
\end{array}$} & \multirow[t]{3}{*}{$\begin{array}{l}\text { Bulk density } \\
\left(\mathrm{g} / \mathrm{cm}^{3}\right)\end{array}$} \\
\hline & \multirow{2}{*}{$\begin{array}{l}\text { Vp Hg } \\
\left(\mathrm{cm}^{3} / \mathrm{g}\right)\end{array}$} & \multirow{2}{*}{$\begin{array}{l}\text { Apparent density } \\
\left(\mathrm{g} / \mathrm{cm}^{3}\right)\end{array}$} & \multicolumn{3}{|c|}{$\%$ Pore volume } & \multirow{2}{*}{$\begin{array}{l}\mathrm{Vp} \mathrm{N} \mathrm{N}_{2} \\
\left(\mathrm{~cm}^{3} / \mathrm{g}\right)\end{array}$} & \multirow{2}{*}{$\begin{array}{l}\mathrm{S}_{\mathrm{BET}} \\
\left(\mathrm{m}^{2} / \mathrm{g}\right)\end{array}$} & \\
\hline & & & $>0.1 \mu \mathrm{m}$ & $0.1-0.01 \mu \mathrm{m}$ & $<0.01 \mu \mathrm{m}$ & & & \\
\hline Reference & 0.0906 & 2.50 & 55.2 & 37.0 & 7.8 & 0.0226 & 3.8 & 2.27 \\
\hline $30 \% \mathrm{RW}$ & 0.0889 & 2.50 & 55.7 & 36.1 & 8.2 & 0.0381 & 6.6 & 2.18 \\
\hline $30 \% \mathrm{FG}$ & 0.1293 & 2.44 & 61.5 & 33.7 & 4.8 & 0.0388 & 5.8 & 2.14 \\
\hline $30 \%$ MIX & 0.1136 & 2.47 & 61.6 & 33.5 & 4.8 & 0.0344 & 4.5 & 2.15 \\
\hline
\end{tabular}


mass losses in Reference sample and a higher value, around $10 \%$, in the admixed ones according to the above commented proportion of wt\% of cement in the composition of specimens.

These temperature ranges for the main peaks detected are similar to the ones detected by TG-DTG-DTA curves for several authors [37-39].

The mass loss of organic material of fibres occurs as a very broad event between 200 and $600{ }^{\circ} \mathrm{C}$ (Fig. 4), and it is not clearly observed in the TG curves thermal analysis of mortars due to the small quantity of fibres mass in the specimen of mortars. The DTA curve of MIX sample mortar shows an exothermal event around $200-350^{\circ} \mathrm{C}$, with a maximum at a $250^{\circ} \mathrm{C}$ in the DTG curve that could account for this combustion.

These results indicate that the inclusion of recycled mineral fibre in mortars does not substantially modify their composition or structure; also, that there are no significant differences between the use of fiberglass or rockwool waste; the MIX sample generally displays behaviour somewhere between that of rockwool and fiberglass samples, which indicates that it would be possible to use a mineral fibre mixture without the need for a separation process.

\subsubsection{Microstructure of the samples}

The microstructure of reference and admixed mortars are very similar and the main values are summarized in Table 3. Fig. 7 show the pore size distribution measured by $\mathrm{Hg}$ porosimetry both in cumulative and differential form.

All mortar samples present similar low values of pore volume, around $0.1 \mathrm{~cm}^{3} / \mathrm{g}$, according to bibliography [40]. The pore volume
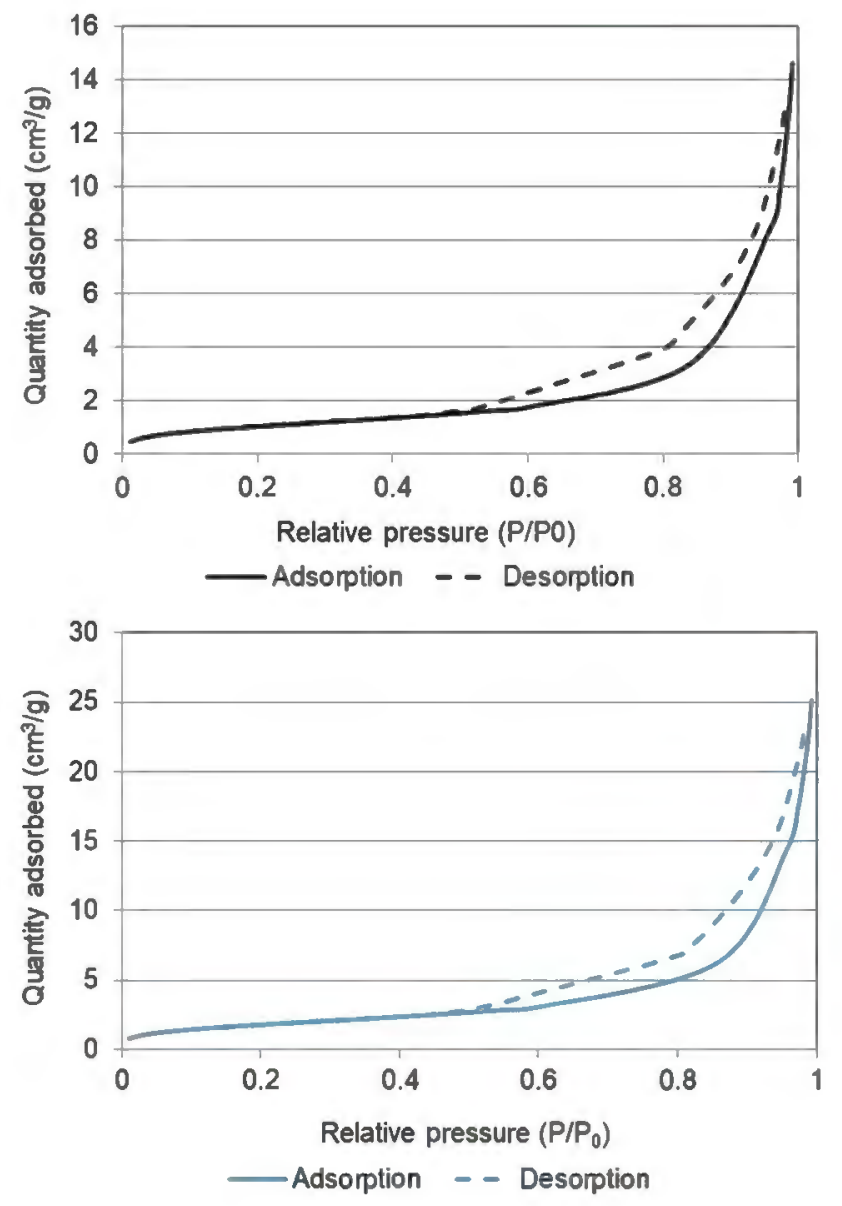

Fig. 8. Isotherms of adsorption-desorption of $\mathrm{N}_{2}$ for reference (top) and $\mathrm{FG}$ admixed mortars (bottom). is a bit higher in the samples including FG and MIX, and accordingly the bulk density (as measured by $\mathrm{Hg}$ porosimetry) are very similar in Reference and RW samples and slightly lower in the samples with FG and MIX. The pore size of all mortars samples is comprised between approximately $0.03 \mu \mathrm{m}$ and $90 \mu \mathrm{m}$ and correspond mainly to capillary pore [41]. Table 3 presents the percentage of pore volume vs. size. A great percentage of the pore volume, around $60 \%$, correspond to large capillary pores (LCPs, with diameter larger than $0.1 \mu \mathrm{m}$ ); around $30 \%$ of the pore volume correspond to small capillary pores (SCPs, with diameter around $\approx 0.01-0.1 \mu \mathrm{m}$ ), and less than $10 \%$ of the pores are smaller than $0.01 \mu \mathrm{m}$.

The admixed mortars with FG and MIX display a slightly higher proportion of LCP. In all samples the proportion of gel pores is very low.

It can be appreciated that all samples present a very similar, bimodal pore size distribution (Fig. $7 \mathrm{~b}$ ), with a broad maximum at around $0.04 \mu \mathrm{m}$ and a sharp one around $0.01 \mu \mathrm{m}$. Considering the size of the particles of sand and fibres (see Table 2), it is clear that the LCPs are not due to the interparticle spaces of these fillers. This is corroborated with the coincidence among the pore size distribution of mortars samples with and without fibres.

Fig. 8 shows the $\mathrm{N}_{2}$ adsorption-desorption isotherms of the Reference and $30 \%$ FG mortars samples as an example. The pore volume and BET surface area calculated from them are displayed in Table 3. The isotherms obtained for the four samples are of type IIb, according to the classification proposed by the IUPAC [42], characteristic of solids that are non-porous or macroporous, in which desorption causes a hysteresis loop at relatively high pressures of above 0.5 , due to capillary condensation of nitrogen in large pores.
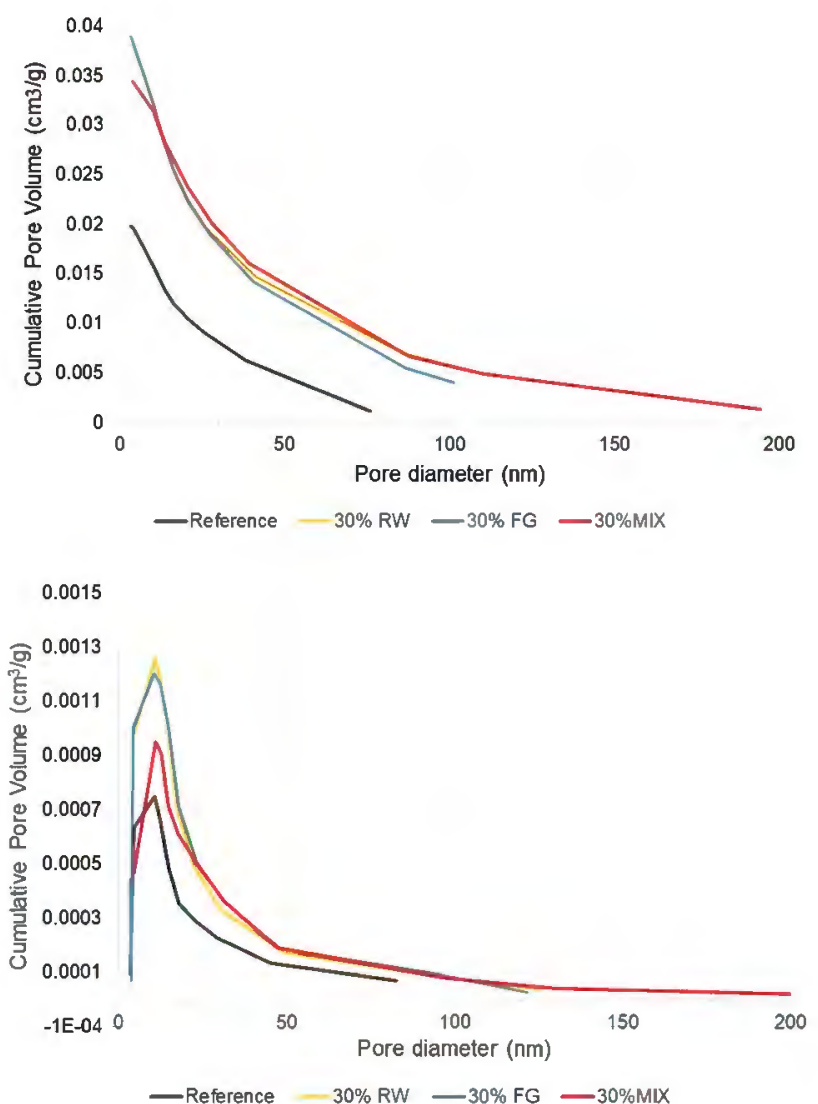

Fig. 9. Cumulative (top) and differential (bottom) pore volume obtained by adsorption-desorption of $\mathrm{N}_{2}$ 

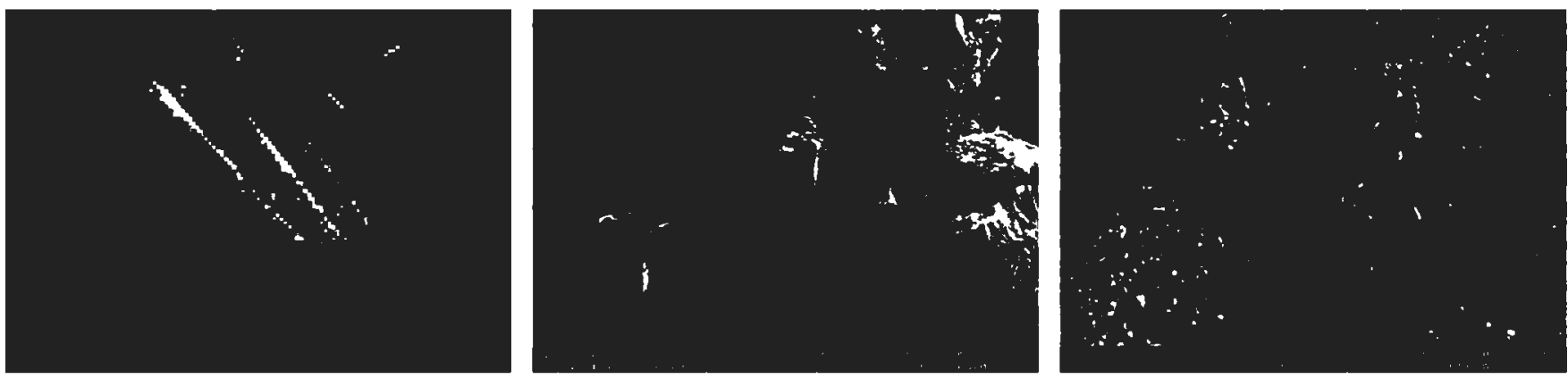

Fig. 10. SEM micrographs for the mortars admixed with fibres (from left to right): RW, FG and MIX.

Accordingly, the pore size distribution obtained from the $\mathrm{N}_{2}$ desorption branch (Fig. 9) prove the absence of micropores (as defined by the IUPAC with diameter less than $2 \mathrm{~nm}$ ) in the studied mortars. The pore volume measured by this technique corresponds to the pores smaller than $100 \mathrm{~nm}$, and then the values are lower than those obtained by the $\mathrm{Hg}$ porosimetry. All the admixed mortars samples present a slightly higher value of pore volume than the reference sample, accompanied with higher BET surface area. The MIX sample presents intermediate values of pore volume and surface area according to the preparation procedure. It is interesting to note that in the range of mesoporous the pore size distribution is practically the same for all samples, both Reference and admixed ones, with a maximum around $10 \mathrm{~nm}$.

These results indicate that the presence of fibres does not affect the setting of the mortar, where the mortar mass is set around the fibres without significant additional porosity occurring in the range of pore size covered by the study; that is, the fibres are "encapsulated" by the set mass, which could suggest good adhesion between the mortar and the fibres. This fibre-mortar coherence is shown in the microphotographs in Fig. 10.

In short, no major differences between the microstructure of the reference mortar and those admixed with fibres were observed, nor between the mortars incorporating different types of fibres. The mortar samples had a high percentage of fibres substituting sand in the mixes, measured by volume (30\%), but it should be noted that these quantities measured in mass are not high values, and consequently they are not sufficient to cause large changes in the final structure of the composite material.

The admixed samples had very slightly higher pore and specific surface area volumes, with the distribution of pore sizes of all the samples being very similar; in particular, mortar with FG additives had the highest values for pore volume and specific surface area. This slight difference resulted in the admixed mortars being slightly lighter, which is evident in the values for apparent density determined for each of the prismatic mortar samples (Table 3 ).

\section{Conclusions}

In general, it can be concluded that both the structure and chemical composition as well as the microstructure of mortars incorporating additive fibres is similar to that of the reference mortar; that is, there was no significant change caused by the addition of these fibres which would affect the functionality of the mortar, meaning that the use of recycled mineral wool as an additive in mortars is feasible.

It was found that in this type of composite material there were minor increases in porosity, and slight decreases in density, which could result in slight decreases in the mechanical properties of the material. However, the mortars incorporating recycled mineral wool wastes are lighter so that they could improve their insulating properties.
At the same time, positive outcomes included the possibility of minimizing environmental impact due, on the one hand, to a reduction in the use of aggregates and, on the other, to the incorporation of mineral wool waste as a secondary raw material, with these mortars serving as a destination for this type of waste. By incorporating mineral wool waste in a cement mortar matrix as a substitute for $30 \%$ of the sand used for its manufacture, we recycled up to $70 \mathrm{~kg}$ of mineral wool per ton of cement.

\section{Conflict of interest}

None.

\section{References}

[1] M. del Río Merino, J. Santa Cruz Astorqui, P. Villoria Sáez, R. Santos Jiménez, M González Cortina, Eco plaster mortars with addition of waste for high hardness coatings, Constr. Build. Mater. 158 (2018) 649-656, https://doi.org/10.1016/ j.conbuildmat.2017.10.037.

[2] P. Villoria Sáez, M. Del Río Merino, C. Porras-Amores, Estimation of construction and demolition waste volume generation in new residential buildings in Spain, Waste Manage. Res. 30 (2012) 137-146, https://doi.org/ $10.1177 / 0734242 \times 11423955$.

[3] R. Carmen, M. María J., P. Manuel A. The influence of natural and synthetic fibre reinforcement on wood-gypsum composites, Open Constr. Build. Technol. J. 11 (2017) 350-362, https://doi.org/10.2174/ 1874836801711010350.

[4] D. Calleja Crespo, La economía circular, la clave del crecimiento sostenible, Cem. y Hormigón. 976 (2016). http://www.cemento-homigon.com/Articulos/ Articulos?id=1061.

[5] C. Cerdan, C. Gazulla, M. Raugei, E. Martinez, P. Fullana-i-Palmer, Proposal for new quantitative eco-design indicators: a first case study, J. Clean. Prod. 17 (2009) 1638-1643, https://doi.org/10.1016/j.jclepro.2009.07.010.

[6] European Commission, Communication (COM(2010) 2020 final) - Europe 2020: A strategy for smart, sustainable and inclusive growth, Bruselas, 2010. https://eur-lex.europa.eu/legal-content/EN/AUTO/?uri=celex:52010DC2020.

[7] M.P. Mercader, M. Marrero, J. Solís, M.V. Montes, A. Ramírez, Cuantificación de los recursos materiales consumidos en la ejecución de la cimentación, Inf. La Construcción. 62 (2010) 125-132, https://doi.org/10.3989/ic.09.000.

[8] Z. Zhao, S. Remond, D. Damidot, W. Xu, Influence of fine recycled concrete aggregates on the properties of mortars, Constr. Build. Mater. 81 (2015) 179186, https://doi.org/10.1016/j.conbuildmat.2015.02.037.

[9] X.E. Castells, Tratamiento y valorización energética de residuos, 2005.

[10] A.M. Papadopoulos, State of the art in thermal insulation materials and aims for future developments, Energy Build. 37 (2005) 77-86, https://doi.org/ 10.1016/j.enbuild.2004.05.006.

[11] L. Bertó Carbó, Nuevos materiales, modelos y técnicas de caracterización en acústica de la edificación y acústica medioambiental, Universidad Politécnica de Valencia, Spain, 2015.

[12] S.R Piñeiro, M. Del Río Merino, C. Pérez García, New plaster composite with mineral wool fibres from CDW recycling, Adv. Mater. Sci. Eng. 2015 (2015), https://dol.org/10.1155/2015/854192.

[13] O. Väntsi, T. Kärki, Mineral wool waste in Europe: a review of mineral wool waste quantity, quality, and current recycling methods, J. Mater. Cycles Waste Manage. (2014) 62-72.

[14] W.T. Lin, A. Cheng, R. Huang, S.Y. Zou, Improved microstructure of cementbased composites through the addition of rock wool particles, Mater. Charact. 84 (2013) 1-9, https://doi.org/10.1016/j.matchar.2013.06.020.

[15] A. Cheng, W.T. Lin, R. Huang, Application of rock wool waste in cement-based composites, Mater. Des. 32 (2011) 636-642, https://doi.org/10.1016/ j.matdes.2010.08.014. 
[16] S. Pavía, B. Toomey, Influence of the aggregate quality on the physical properties of natural feebly-hydraulic lime mortars, Mater. Struct. 41 (2008) 559-569.

[17] B. Mobasher, S.P. Shah, Test parameters for evaluating toughness of glass-fiber reinforced concrete panels, ACl Mater. I. 86 (1989) 448-458.

[18] C. Junco, J. Gadea, A. Rodríguez, V. Calderón, Cement \& concrete composites durability of lightweight masonry mortars made with white recycled polyurethane foam, Cem. Concr. Compos. 34 (2012) 1174-1179, https://doi. org/10.1016/j.cemconcomp.2012.07.006.

[19] M. Yates, M.A. Martín-Luengo, J. Cornejo, V. González, The importance of the porosity of mortars, tiles and bricks in relation to their bonding strengths, Stud. Surf. Sci. Catal. (1994) 781-790, https://doi.org/10.1016/S0167-2991(08) 63141-9.

[20] M.L. Sánchez Paradela, V. Sănchez Gálvez, Comportamiento a tracción de cementos reforzados con fibras de vidrio, Inf. La Construcción. 43 (1991) 7789, https://oi.org/10.3989/ic.1991.v43.i413.1379.

[21] A. Enfedaque, J.C. Gálvez, F. Suárez, Analysis of fracture tests of glass fibre reinforced cement (GRC) using digital image correlation, Constr. Build. Mater. 75 (2015) 472-487, https://doi.org/10.1016/j.conbuildmat.2014.11.031.

[22] S. Romaniega Piñeiro, Refuerzo de escayola mediante fibras de lana mineral procedentes del reciclaje de RCD, Universidad Politếcnica de Madrid, Spain, 2016.

[23] O. Väntsi, T. Kärki, Utilization of recycled mineral wool as filler in woodpolypropylene composites, Constr. Build. Mater. 55 (2014) 220-226, https:// doi.org/10.1016/j.conbuildmat.2014.01.050.

[24] M del Río Merino, J. Santa Cruz Astorqui, M. González Cortina Morteros aligerados con arcilla expandida: influencia de la granulometría y la adicción de fibras de vidrio AR en el comportamiento mecánico, Inf. La Construcción. 57 (2005) 39-46, https:/doi.org/10.3989/ic.2005.v57.i497.466.

[25] M.L. Sánchez Paradela, A. Del Âguila, El envejecimiento de las pastas de cemento reforzadas con fibras de vidrio, Inf. La Construcción. 42 (1992) 65-71, https://doi.org/10.3989/mc.1992.v42.i226.712.

[26] F. Puertas, T. Amat, T. Vazquez, Comportamiento de morteros de cementos alcalinos reforzados con fibras acrílicas y de polipropileno, Mater. construcción. 50 (2000) 69-84. http://materconstrucc.revistas.csic.es. recursos.biblioteca.upc.edu/index.php/materconstrucc/article/view/400/446.

[27] H.R. Pakravan, M. Jamshidi, M. Latifi, Investigation on polymeric fibers as reinforcement in cementitious composites: flexural performance, J. Ind. Text. 42 (2012) 3-18.

[28] UNE-EN 1015-2:1999, Methods of test for mortar for masonry. Part 2: Bulk sampling of mortars and preparation of test mortars, 1999.

[29] UNE-EN 1015-11:2000, Methods of test for mortar for masonry. Part 11: Determination of flexural and compressive strength of hardened mortar, 2000.
[30] J.M. Cáceres, I.E.G. Hernández, J.M. Rincón, Characterization of fibers as rockwool for insulation obtained from Canary lslands basalts, Mater. Constr. 46 (1996) 61-78.

[31] B.P. Jelle, Traditional, state-of-the-art and future thermal building insulation materials and solutions - properties, requirements and possibilities, Energy Build. 43 (2011) 2549-2563, https://doi.org/10.1016/j.enbuild.2011.05.015.

[32] C. Siligardi, P. Miselli, E. Francia, M. Lassinantti Gualtieri, Temperature-induced microstructural changes of fiber-reinforced silica aerogel (FRAB) and rock wool thermal insulation materials: a comparative study, Energy Build. 138 (2017) 80-87, https://doi.org/10.1016/j.enbuild.2016.12.022.

[33] V.S. Ramachandran, J.J. Beaudoin (Eds.), Handbook of Analytical Techniques in Concrete Science and Technology, William Andrew Publishing/Noyes Publications, New York, 2001.

[34] M. Carsana, M. Frassoni, L. Bertolini, Comparison of ground waste glass with other supplementary cementitious materials, Cem. Concr. Compos. 45 (2014) 39-45, https://doi.org/10.1016/j.cemconcomp.2013.09.005.

[35] V.S. Ramachandran, R.M. Paroli, J.J. Beaudoin, A.H. Delgado, Formation and Hydration of Cement and Cement Compounds, in: Handb. Therm. Anal. Constr. Mater., William Andrew Inc., 2002, pp. 71-142, https://doi.org/10.1016/B978081551487-9.50001-3.

[36] W.T. Lin, A. Cheng, R. Huang, Y.C. Wu, T.Y. Han, Rock wool wastes as a supplementary cementitious material replacement in cement-based composites, Comput. Concr. 11 (2013) 93-104, https://doi.org/ 10.12989/cac.2013.11.2.093.

[37] A. Chaipanich, T. Nochaiya, Thermal analysis and microstructure of Portland cement-fly ash-silica fume pastes, J. Therm. Anal. Calorim. 99 (2010) 487 493, https://doi.org/10.1007/s10973-009-0403-y.

[38] K.Vessalas, P.S. Thomas, A.S. Ray, J.P. Guerbois, P. Joyce, J. Haggman, Pozzolanic reactivity of the supplementary cementitious material pitchstone fines by thermogravimetric analysis, J. Therm. Anal. Calorim. 97 (2009) 71-76, https:// doi.org/10.1007/s10973-008-9708-5.

[39] I. Pane, W. Hansen, Investigation of blended cement hydration by isotherma calorimetry and thermal analysis, Cem. Concr. Res. 35 (2005) 1155-1164 https://doi.org/10.1016/j.cemconres.2004.10.027.

[40] J. Gallego Punzano, Empleo de adsorbentes como aditivos en cementos: caracterización y aplicaciones en la eliminación de contaminantes ambientales, Universidad de Oviedo, Spain, 2014.

[41] H.M. Jennings, J.W. Bullard, From electrons to infrastructure: engineering concrete from the bottom up, Cem. Concr. Res. 41 (2011) 727-735, https://doi org/10.1016/j.cemconres.2011.03.025.

[42] F. Rouquerol, J. Rouquerol, K.S.W.Sing, P. Llewellyn, G. Maurin, in: Adsorption by Powders and Porous Solids. Principles, Methodology and Applications, second ed., Elsevier Ltd, 2014, https:/doi.org/10.1016/B978-0-08-097035-6.09991-5. 